\title{
Anomalous muscle bundle of the right ventricle Its recognition and surgical treatment
}

\author{
M. D. LI, J. C. COLES, AND A. C. MCDONALD
}

From the Department of Paediatrics, Department of Cardiovascular Surgery, Department of Diagnostic Radiology, University of Western Ontario, London, Ontario, Canada

SUMMARY This communication presents our experience with 14 cases of congenital heart disease associated with anomalous muscle bundle inside the right ventricular cavity dividing it into two chambers. The clinical picture, natural history, and diagnostic characteristics are described. It can be diagnosed by right ventricular cineangiogram in the anteroposterior position. It can be resected surgically, safely.

Anomalous muscle bundles when found in the right ventricle are generally of little functional significance. On the other hand a muscle bundle situated across the main channel of the right ventricular cavity can, when it becomes hypertrophied, obstruct the circulatory pathway from the tricuspid to pulmonary valve (Fig. 1). The syndrome of anomalous muscle bundle dividing the right ventricle into 2 pressure chambers (2-chambered right ventricle) was first described by Tsifutis et al. (1961) and subsequently by various authors (Lucas et al., 1962; Hartmann et al., 1964; Perloff et al., 1965; Hindle et al., 1968; Hartmann et al., 1970; Barnes et al., 1971; Patel and Astley, 1973). This anomalous muscle bundle is quite different from the well-known secondary infundibular hypertrophy occurring in many patients with ventricular septal defect, pulmonary stenosis, and tetralogy of Fallot, though both can occur in the same patient. The anomalous muscle bundle is triangular in shape, with its apex attached to the anterior aspect of the ventricular septum immediately above and in front of the ventricular septal defect. It crosses the right ventricular chamber to insert at the apical portion of the anterior wall of the right ventricle. It is important to recognise this muscle bundle during preoperative assessment, as failure to do so could lead to incomplete repair of the defect or even death of the patient (Patel and Astley, 1973).

\section{Subjects and methods}

This report describes 14 such cases encountered at the Victoria Hospital, War Memorial Children's Hospital Complex, London, Ontario, from January

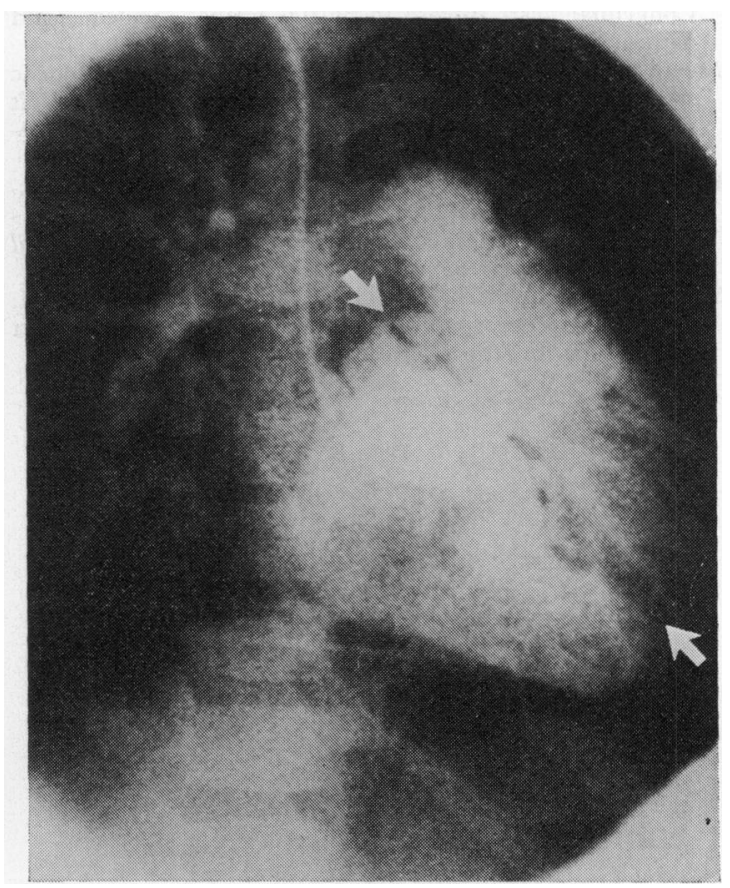

Fig. 1 Right ventricular cineangiogram, anteroposterior view, showing anomalous muscle bundle dividing the right ventricular cavity into two chambers.

1972 to January 1977. Eleven patients have been operated upon successfully with no mortality. $\frac{.}{\Phi}$ Seven have had two or more cardiac catheterisations. $\stackrel{\text { S }}{\rightarrow}$ In 8 operated cases, the diagnosis was made by 0 cardiac catheterisation (Table 1 ). The abnormality $\overline{0}$ was not suspected before surgery in the other $3 \vec{\triangle}$ patients principally because we did not have $\frac{\vec{\Phi}}{\mathbb{Q}}$ adequate right ventricular angiograms (Table 2). 음 
Table 1 Clinical and haemodynamic data of patients with diagnosis of anomalous muscle bundle (AMB) made during cardiac catheterisation and confirmed by surgery

\begin{tabular}{|c|c|c|c|c|c|c|}
\hline $\begin{array}{l}\text { Case } \\
\text { no. }\end{array}$ & $\begin{array}{l}\text { Age } \\
(y)\end{array}$ & Procedure & $\begin{array}{l}\text { Cardiac } \\
\text { malformation }\end{array}$ & $\begin{array}{l}\text { Pressure gradient } \\
\text { across } A M B \\
(m m H g)\end{array}$ & $Q_{p} / Q$ & Angiographic findings \\
\hline 1 & $\begin{array}{r}3 / 12 \\
59 / 12 \\
59 / 12 \\
611 / 12\end{array}$ & $\begin{array}{l}\text { Cath. } \\
\text { Recath. } \\
\text { Surgery }\end{array}$ & VSD & $\begin{array}{r}0 \\
108\end{array}$ & $\begin{array}{l}2 \cdot 8 / 1 \\
1 \cdot 1 / 1\end{array}$ & $\begin{array}{l}\text { VSD (?) AMB } \\
\text { VSD AMB }\end{array}$ \\
\hline 2 & $\begin{array}{l}611 / 12 \\
42 / 12 \\
43 / 12\end{array}$ & $\begin{array}{l}\text { Recath. } \\
\text { Cath. } \\
\text { Surgery }\end{array}$ & VSD & $\begin{array}{l}11 \\
65\end{array}$ & $\begin{array}{l}1 / 1 \\
1 \cdot 2 / 1\end{array}$ & $\begin{array}{l}\text { Residual AMB } \\
\text { VSD, AMB }\end{array}$ \\
\hline 3 & $\begin{array}{l}5 \\
6\end{array}$ & $\begin{array}{l}\text { Recath. } \\
\text { Cath. }\end{array}$ & Tetralogy & $\begin{array}{r}0 \\
52\end{array}$ & $\begin{array}{l}\text { 1/1 } \\
\text { Bidirectional }\end{array}$ & $\begin{array}{l}\text { Insignificant VSD } \\
\text { VSD, AMB, Right aortic } \\
\text { arch }\end{array}$ \\
\hline & $\begin{array}{l}6 \\
610 / 12\end{array}$ & $\begin{array}{l}\text { Surgery } \\
\text { Recath. }\end{array}$ & & 20 & $1 / 1$ & $\begin{array}{r}\text { Right aortic arch } \\
\text { Minimal AMB }\end{array}$ \\
\hline 4 & $\begin{array}{l}58 / 12 \\
58 / 12\end{array}$ & $\begin{array}{l}\text { Cath. } \\
\text { Surgery }\end{array}$ & VSD & 40 & $2 / 1$ & VSD, AMB \\
\hline 5 & $\begin{array}{l}61 / 12 \\
61 / 12\end{array}$ & $\begin{array}{l}\text { Cath. } \\
\text { Surgery }\end{array}$ & VSD & 33 & $1 \cdot 8 / 1$ & VSD, AMB \\
\hline 6 & $\begin{array}{l}185 / 12 \\
255 / 12 \\
257 / 12\end{array}$ & $\begin{array}{l}\text { Cath. } \\
\text { Recath. } \\
\text { Surgery }\end{array}$ & VSD & $\begin{array}{l}60 \\
72\end{array}$ & $\begin{array}{l}1.8 / 1 \\
1 \cdot 7 / 1\end{array}$ & $\begin{array}{l}\text { VSD, AMB } \\
\text { VSD, AMB }\end{array}$ \\
\hline 7 & & $\begin{array}{l}\text { Cath. } \\
\text { Surgery }\end{array}$ & VSD & 65 & $1 \cdot 7 / 1$ & VSD, AMB \\
\hline 8 & $\begin{array}{l}23 \\
48 / 12 \\
410 / 12\end{array}$ & $\begin{array}{l}\text { Recath. } \\
\text { Cath. } \\
\text { Surgery }\end{array}$ & Pulm. sten. & $\begin{array}{r}15 \\
0\end{array}$ & $\begin{array}{l}1 \cdot 1 / 1 \\
1 / 1\end{array}$ & $\begin{array}{l}\text { Small VSD } \\
\text { Pulm. val. sten., AMB }\end{array}$ \\
\hline
\end{tabular}

Table 2 Clinical and haemodynamic data of patients with anomalous muscle bundle (AMB) found during surgery

\begin{tabular}{|c|c|c|c|c|c|c|}
\hline $\begin{array}{l}\text { Case } \\
\text { no. }\end{array}$ & $\begin{array}{l}\text { Age } \\
(y)\end{array}$ & Procedure & $\begin{array}{l}\text { Cardiac } \\
\text { malformation }\end{array}$ & $\begin{array}{l}\text { Pressure gradient } \\
\text { across } A M B(m m H g)\end{array}$ & $Q_{p} / Q_{s}$ & $\begin{array}{l}\text { Angiographic } \\
\text { findings }\end{array}$ \\
\hline 9 & $\begin{array}{l}410 / 12 \\
5\end{array}$ & $\begin{array}{l}\text { Cath. } \\
\text { Surgery }\end{array}$ & VSD + AR & 26 & $1 \cdot 8 / 1$ & VSD, AR \\
\hline \multirow[t]{2}{*}{10} & $55 / 12$ & Cath. & Tetralogy & 0 & Bidirectional & $\begin{array}{l}\text { VSD Pulm. val. + } \\
\text { Inf. sten. }\end{array}$ \\
\hline & $\begin{array}{rl}7 & 11 / 12 \\
13 & 6 / 12 \\
16 & 4 / 12\end{array}$ & $\begin{array}{l}\text { Surgery } \\
\text { Recath. } \\
\text { Surgery }\end{array}$ & & 25 & $2 / 1$ & Reopened VSD \\
\hline 11 & $\begin{array}{l}75 / 12 \\
75 / 12\end{array}$ & $\begin{array}{l}\text { Cath. } \\
\text { Surgery }\end{array}$ & $\mathbf{V S D}+\mathbf{A R}$ & 26 & $1 \cdot 6 / 1$ & VSD, AR \\
\hline
\end{tabular}

AR, aortic regurgitation.

Table 3 Clinical and haemodynamic data of patients with anomalous muscle bundle $(A M B)$ diagnosed by angiogram, awaiting surgery

\begin{tabular}{|c|c|c|c|c|c|c|}
\hline $\begin{array}{l}\text { Case } \\
\text { no. }\end{array}$ & $\begin{array}{l}\text { Age } \\
(y)\end{array}$ & Procedure & Cardiac malformation & $\begin{array}{l}\text { Pressure gradient } \\
\text { arross } A M B(m m H g)\end{array}$ & $Q_{p} / Q_{s}$ & $\begin{array}{l}\text { Angiographic } \\
\text { findings }\end{array}$ \\
\hline 12 & 4 & Cath. & VSD + PS & 20 & $1 \cdot 2 / 1$ & $\begin{array}{l}\text { VSD, ASD, PS, } \\
\text { AMB }\end{array}$ \\
\hline 13 & $\begin{array}{l}66 / 12 \\
76 / 12 \\
36 / 12\end{array}$ & $\begin{array}{l}\text { Cath. } \\
\text { Surgery } \\
\text { Recath. }\end{array}$ & VSD & $\begin{array}{r}0 \\
20\end{array}$ & $\begin{array}{l}2 \cdot 3 / 1 \\
1 \cdot 6 / 1\end{array}$ & $\begin{array}{l}\text { VSD } \\
\text { Reopened VSD, } \\
\text { AMB }\end{array}$ \\
\hline 14 & 25 & Cath. & VSD & 20 & $1 / 1$ & $\begin{array}{l}\text { AMB membranous } \\
\text { systol aneurysm } \\
\text { (VSD spon- } \\
\text { taneous closure }\end{array}$ \\
\hline
\end{tabular}

Three patients in whom the anomalous muscle bundle was diagnosed by cardiac catheterisation and angiography are now waiting for surgical confirmation (Table 3).

Of these 14 cases in the series, 11 were associated with isolated ventricular septal defect, 2 with tetralogy of Fallot, and 1 with pulmonary valve stenosis. The age of discovery of the anomaly, findings at cardiac catheterisation and angiography, and the age at operation in each case are summarised 


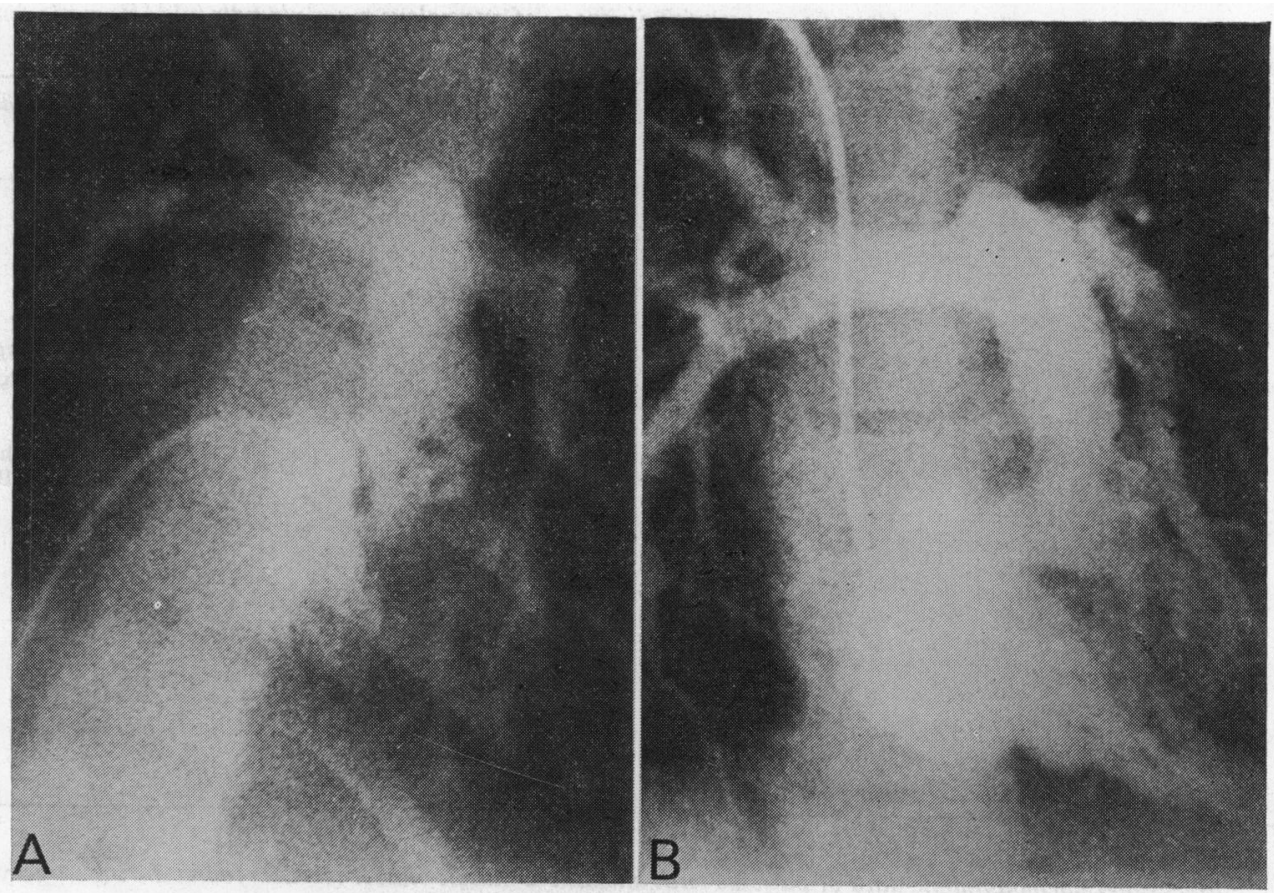

in Tables 1, 2, and 3. Five of the cases are described in more detail.

\section{Case reports}

\section{CASE 1}

This child, date of birth 20 October 1966, was found to have a heart murmur at 6 weeks of age. The first admission was at 3 months of age for congestive heart failure. He was treated with digitalis. At that time a pansystolic murmur with thrill was noticed at the left lower sternal border with a mid-diastolic murmur at the apex suggesting a large left-to-right shunt at ventricular level. Chest $x$-ray film showed cardiac enlargement with pulmonary plethora. Electrocardiogram showed evidence of left ventricular hypertrophy. Cardiac catheterisation showed a large ventricular septal defect with pulmonary/ systemic flow ratio of $2 \cdot 8: 1$. There was a systolic pressure gradient of $10 \mathrm{mmHg}$ across the pulmonary outflow tract. Selective right ventricular angiogram showed a shadow in the right ventricular cavity suggesting an anomalous muscle bundle (Fig. 2A). On follow-up examination the congestive heart failure improved. The digitalis was discontinued at 18 months of age.

He was readmitted to the hospital active and well

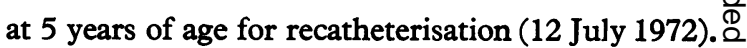
Examination again revealed a long systolic murmur $\overrightarrow{\vec{O}}$ with thrill located maximally at the second and 3 third left intercostal space slightly lateral to the left sternal border but inside the left midclavicular line. The second sound split widely and moved

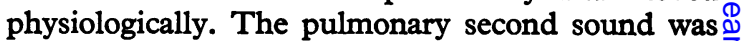
slightly soft. Chest $x$-ray film showed a normal $\frac{7}{\sigma}$ heart size with prominent main pulmonary artery 3 . segment. An electrocardiogram showed combined right and left ventricular hypertrophy. Recathe- 3 terisation at this time showed a small ventricularo septal defect with pulmonary/systemic flow ratio of $1 \cdot 1: 1$. There was a systolic pressure gradient of $110 \mathrm{mmHg}$ across the anomalous muscle bundle. Selective right ventricular angiogram in the antero- $O$ posterior position showed a large muscle bundle N inside the right ventricle dividing the right ventricle into two parts (Fig. 2B). An aneurysm of the membranous ventricular septum was also noted He was operated upon at 5 years 9 months of age. $\frac{\bar{\Phi}}{1}$ The ventricular septal defect was repaired and the anomalous muscle bundle was resected. $\mathrm{He}$ was 0 recatheterised 14 months after the operation. Noo

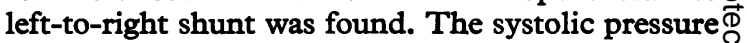
gradient across the anomalous muscle bundle had $\mathbb{D}$ reduced to $10 \mathrm{mmHg}$. Right ventricular angiogram $\frac{\varrho}{\sigma}$ 


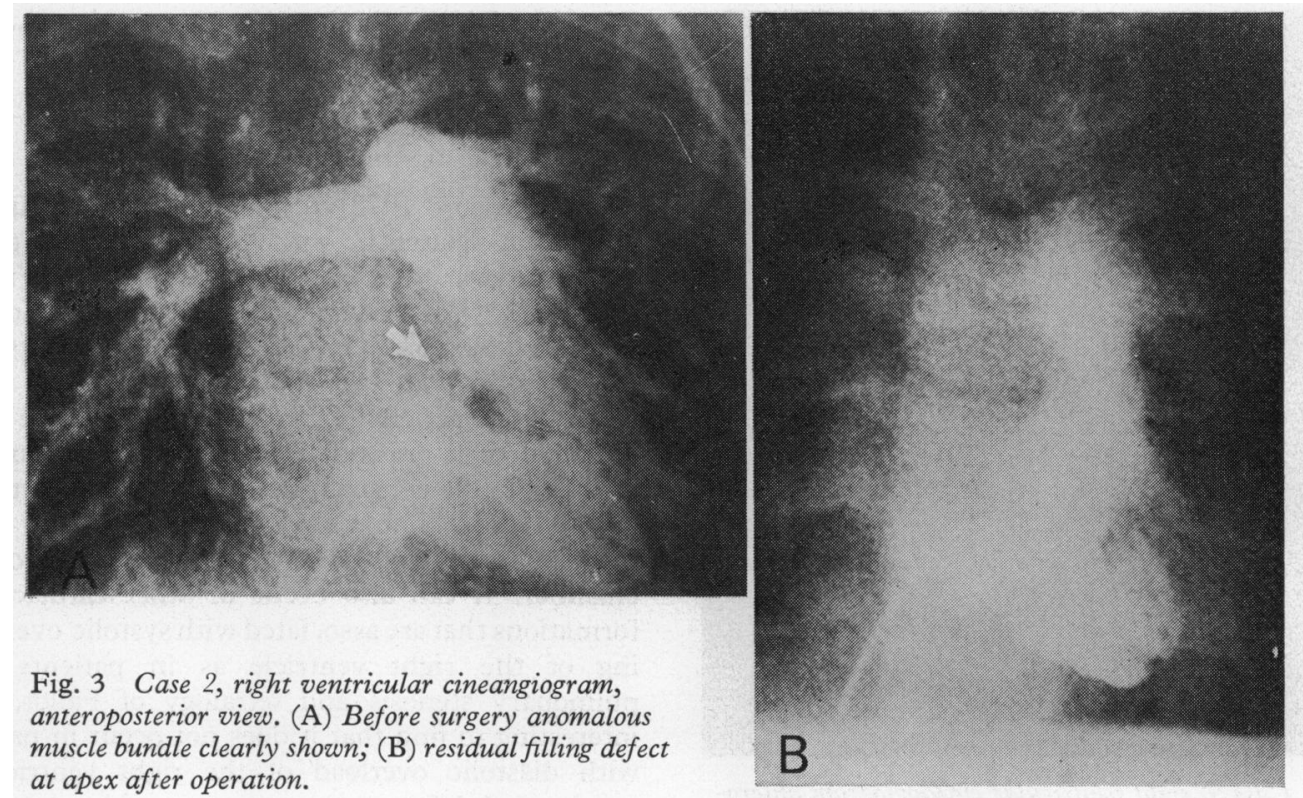

did show a residual filling defect representing the remains of the muscle bundle.

\section{CASE 2}

This boy, date of birth 24 August 1968, had a heart murmur noticed at 2 weeks of age. At that time the clinical diagnosis of ventricular septal defect was made. He became cyanotic at the age of 3 . At 4 years 2 months, examination revealed a long systolic murmur at the second and third left intercostal spaces with a soft pulmonary second sound. $X$-ray film showed minimal cardiac enlargement with prominent main pulmonary artery segment. Electrocardiogram showed right atrial hypertrophy and combined ventricular hypertrophy. Cardiac catheterisation was performed on 22 October 1972. A ventricular septal defect with pulmonary/systemic flow ratio of 1.2:1 was found. There was a systolic pressure gradient of $65 \mathrm{mmHg}$ across the mid right ventricular region. Right ventricular angiogram showed a two-chambered right ventricle with a good sized ventricular septal defect (Fig. 3A). He was operated upon at 4 years 3 months of age. He was recatheterised 9 months later. There was no shunt, nor was there any residual pressure gradient within the ventricle. Right ventricular angiogram still showed a minimal filling defect (Fig. 3B).

\section{CASE 3}

This boy, date of birth 19 October 1966, was discovered to have a heart murmur at 9 months of age. He became cyanotic at 2 years of age. He was first seen at 5 years of age with the complaint of increasing exercise intolerance. Examination at that time revealed a single second sound. Cardiac catheterisation performed at 6 years of age showed a ventricular septal defect with pulmonary valve stenosis. A right aortic arch was also noted. A systolic pressure gradient of $52 \mathrm{mmHg}$ was noticed across the mid right ventricular region. Right ventricular angiogram showed a normal right ventricular infundibulum with no evidence of infundibulum stenosis. An anomalous muscle bundle was seen inside the right ventricular body. Total correction was performed at the age of 6 . Recatheterisation 10 months after operation showed that the systolic pressure gradient across the anomalous muscle bundle had been reduced to $20 \mathrm{mmHg}$. Right ventricular angiogram did show a minimal residual filling defect with no evidence of a shunt.

\section{CASE 9}

This girl, date of birth 19 May 1968, had a ventricular septal defect diagnosed at 3 days of age. Aortic regurgitation became evident on follow-up. She was catheterised at 4 years 10 months of age. On pull-back tracing there was a systolic pressure gradient of $26 \mathrm{mmHg}$ at the mid right ventricular level. Right ventricular angiogram was performed with the tip of the catheter in the distal chamber. A straight line could be seen in the mid right ventricle separating the outflow chamber from the 


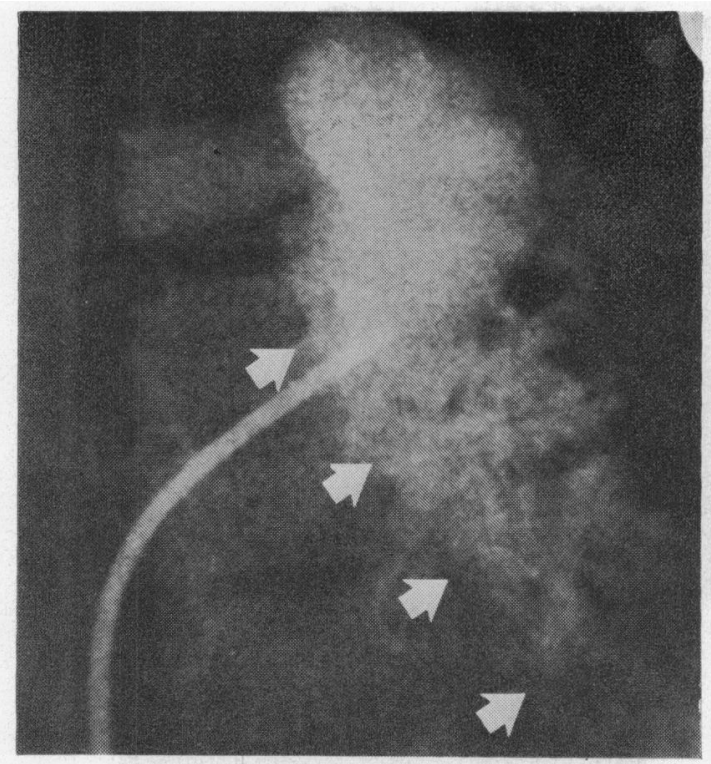

Fig. 4 Case 9, right ventricular cineangiogram anteroposterior view, with contrast medium injected into the distal chamber. A straight line divides the two chambers signifying the position of the anomalous muscle bundle.

inflow chamber and signifying the position of the anomalous muscle bundle (Fig. 4). On operation the anomalous muscle bundle was found and was resected. A ventricular septal defect with a pulmonary/systemic flow ratio of $1 \cdot 8: 1$ was repaired. Catheterisation has not been repeated.

\section{CASE 11}

A girl, date of birth 6 December 1965, had a heart murmur noticed soon after birth and the clinical diagnosis was ventricular septal defect. She remained asymptomatic. At $7 \frac{1}{2}$ years of age cardiac catheterisation showed a ventricular septal defect with aortic regurgitation. The pulmonary/systemic flow ratio was $1 \cdot 6: 1$. On pull-back tracing there was a systolic pressure gradient of $26 \mathrm{mmHg}$ at mid right ventricular level. Right ventricular angiogram was performed with the patient in the right anterior oblique position. The right ventricular outflow tract was found to be wide open with no significant obstruction. She was operated upon 2 days later. A subpulmonary ventricular septal defect was patched. In mid right ventricle a hypertrophied anomalous muscle bundle was found and resected. This case showed that the anomalous muscle bundle could be seen only with the patient in the anteroposterior position. In the right anterior oblique position or lateral position the anomalous muscle bundle could not be seen clearly.

\section{Discussion}

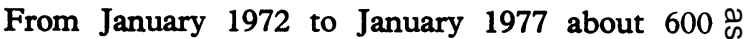
paediatric patients with significant congenital $\overrightarrow{0}$ heart disease were catheterised at the Victoria Hospital, War Memorial Children's Hospital $\vec{\omega}$ Complex, London, Ontario. Fourteen patients were found to have an anomalous muscle bundle inside the right ventricle. This condition may be more $\overrightarrow{0}$ common than previously believed. The anomalous 0 muscle bundle is usually associated with ventricular $\overrightarrow{0}$ septal defect. The ventricular septal defect com- $\stackrel{f}{0}$ monly opens into the high pressure proximal $\frac{9}{5}$ chamber. It can also occur in other cardiac mal- formations that are associated with systolic overload- $D$ ing of the right ventricle as in patients with $\frac{\mathbb{O}}{\mathbb{D}}$ pulmonary stenosis and tetralogy of Fallot. It is interesting to find that it does not occur in patients with diastolic overload of the right ventricle in atrial septal defect.

All of our patients probably had a ventricular septal defect to start with. Some of them had congestive heart failure in early infancy but improved with time and increasing obstruction by the hypertrophied muscle bundle. We believe that this anomalous muscle bundle is present at birth with no obstruction of the blood flow, but with time and pressure overloading of the right ventricle, the muscle bundle hypertrophies and the pressure gradient increases. This is well illustrated in case 1. Four of our patients had repeated cardiac catheterisation which confirmed that the pressure gradient across the anomalous muscle bundle may increase with time. The degree of obstruction produced may be minimal to severe. The systolic murmur is usually long with an ejection quality and associated with a thrill maximum at the third left intercostal space. The second sound is split widely and moves physiologically with respiration. Chest $x$-ray film and electrocardiogram are not very helpful in making the diagnosis.

Cardiac catheterisation usually shows a pressure gradient at mid right ventricular level. Often it is difficult to get the tip of the catheter through the opening between the proximal and distal chamber into the right ventricular outflow tract. On pullback tracing the low pressure outflow chamber is excessively long. Catheter manipulation below the pulmonary valve is less likely to cause troublesome extrasystoles and other arrhythmias than in cases of secondary hypertrophy of the right ventricular infundibulum. The diagnosis is best made by right ventricular angiography with the patient in the 
anteroposterior position. The contrast medium should, however, be injected into the proximal chamber in order to see clearly the anomalous muscle bundle. The anomalous muscle bundle is poorly visualised or may be missed entirely in lateral and left or right anterior oblique views. The anomaly may also be missed if the contrast medium is injected into the distal chamber of the right ventricle. In this event it will be found that the infundibulum is wide open and the discovery of the pressure gradient will be puzzling. However, a straight oblique line running upwards and to the left from the region of the apex should make one suspicious of a dividing bundle between the proximal and distal chamber of the right ventricle which should not be confused with the tricuspid valve.

Surgically, we have found it most convenient to enter the right ventricle below and to the right of the anomalous muscle bundle using a paracoronary incision. In this way the anomalous band is readily identified and can be completely removed. The recognition of the anomalous muscle bundle is extremely important as in its most developed stage it may resemble a ventricular septum with an associated defect. Closure of this opening would, of course, be a catastrophe. After the muscle bundle is completely removed the ventricular septal defect and/or other anomalies are corrected by conventional techniques. After closure of the right ventriculotomy, pressures are taken in both sections of the right ventricle; if there is any significant gradient cardiac pulmonary bypass is reinstituted and the ventriculotomy reopened. The removal of the anomalous muscle bundle of the abnormal band is usually very straightforward provided it is suspected and recognised before the operation.

Of 11 patients operated upon there has been no mortality. Postoperatively there was no major conductive disturbance. We believe that the surgical treatment of patients with an anomalous muscle bundle carries no higher risk than those without the band.

\section{Conclusions}

It seems probable that this relatively common condition is present at birth but without significant pressure gradient. With time and pressure overloading of the right ventricle, the muscle bundle may hypertrophy and a pressure gradient develops. Usually the cause of the overload is a ventricular septal defect but other defects can have the same effect. An anomalous muscle bundle can be diagnosed reliably by a good right ventricular angiogram in the anteroposterior position and can be resected surgically safely. It should not be confused with the localised right ventricular infundibular stenosis seen in tetralogy of Fallot.

\section{References}

Barnes, R. J., Kwong, K. H., and Cheung, A. C. S. (1971). Aberrant muscle bundle of the right ventricle. British Heart fournal, 33, 546-551.

Hartmann, A. F., Jr., Goldring, D., and Carlsson, E. (1964). Development of right ventricular obstruction by aberrant muscular bands. Circulation, 30, 679-685.

Hartmann, A. F., Jr., Goldring, D., Ferguson, T. B., Burford, T. H., Smith, C. H., Kissane, J. M., and Frech, R. S. (1970). The course of children with the two-chambered right ventricle. Fournal of Thoracic and Cardiovascular Surgery, 60, 72-83.

Hindle, W. V., Jr., Engle, M. A., and Hagstrom, J. W. C. (1968). Anomalous right ventricular muscles. American fournal of Cardiology, 21, 487-495.

Lucas, R. V., Jr., Varco, R. L., Lillehei, C., Adams, P., Jr., Anderson, R. C., and Edwards, J. E. (1962). Anomalous muscle bundle of the right ventricle. Circulation, 25, 443-455.

Patel, R., and Astley, R. (1973). Right ventricular obstruction due to anomalous muscle bands. British Heart fournal, 35, 890-893.

Perloff, J. K., Ronan, J. A., Jr., and De Leon, A. C. (1965). Ventricular septal defect with the 'two-chambered right ventricle'. American fournal of Cardiology, 16, 894-900.

Tsifutis, A. A., Hartmann, A. F., Jr., and Arridsson, H. (1961). Two chambered right ventricle: report on seven patients (abstract). Circulation, 24, 1058.

Requests for reprints to $\mathrm{Dr}$ M. D. Li, War Memorial Children's Hospital, 392 South Street, London, Ontario, Canada N6B 1 B8. 